\title{
Effects of nursing care planning tools on nurses' and residents' quality of life in long-term care facilities: A literature review
}

\author{
Astrid Herold-Majumdar ${ }^{* 1,2}$, Michael Schaller ${ }^{1}$, Steffen Fleischer ${ }^{3}$, Johann Behrens ${ }^{3}$ \\ ${ }^{1}$ Faculty of Applied Social Sciences, Nursing Science, University of Applied Sciences Munich, München, Germany \\ ${ }^{2}$ STTI, University of South Carolina, Aiken, United States \\ ${ }^{3}$ Martin-Luther-Universität Halle-Wittenberg, Halle (Saale), Germany
}

Received: July 25, 2016

DOI: $10.5430 /$ jnep.v7n4p 32
Accepted: October 31, 2016

Online Published: November 22, 2016

\begin{abstract}
Introduction: Health-care providers invest substantial resources for nursing care planning (NCP) and documentation. Its effectiveness is varying. In this review nursing care planning tools (NCPT) are considered as a technology supporting the nurses in their daily working life and simultaneously supporting residents in their daily life in the nursing home. The purpose of this literature review is to identify studies verifying the effects of NCPT on user's quality of life (QoL) as a relevant outcome in long-term care. End-users are nurses who work with these tools and residents who are affected directly and indirectly by NCPT. Methods: A literature review with a peer-review system from 1995 to 2014 of 6 electronic databases (PSYNDEX, WISO-Net, PubMed, CINAHL, GeroLit, Cochrane Library) was performed. In addition, a hand search in scientific journals for nursing was conducted and snowball strategies were used such as screening the reference lists of eligible papers, reviewing grey literature and contacting experts in the field. The screening process follows PRISMA-systematic. Studies with mixed-method designs were included. Methodological quality of records was assessed by criteria of SQUIRE guidelines and ENTREQ and ranked by Evans' hierarchy of evidence.

Results: Out of 1,190 matches, 205 full-texts were analysed and 6 records has been included. Due to varying methods of these studies no meta-analysis could be conducted and main results were narratively summarized by content analysis. Quality of life as a holistic concept was not found as primary endpoint. But for relevant quality of life related factors, NCPT based on NANDA-I diagnoses and comprehensive nursing diagnoses seem to have desirable effects on QoL.

Conclusions: More user-oriented research with the focus on end-user's quality of life is needed for investigating the effects of nursing care planning tools. Mixed-method designs including qualitative studies should be used for taking into consideration user's perspective and perception.
\end{abstract}

Key Words: Nursing care plan, Quality of life, Quality of working life, Long-term care, Literature review

\section{INTRODUCTION}

Healthcare providers invest substantial resources for nursing care planning (NCP). Electronic or paper-based tools and licences must be bought, staff must be trained, and nurses invest considerable time in planning and documenting their work with these tools. The reported time required for these ranges between $5 \%^{[1]}$ and $29 \%^{[2]}$ of daily working hours. The effects on relevant outcomes such as quality of life (QoL)

*Correspondence: Astrid Herold-Majumdar; Email: astrid.herold-majumdar@hm.edu; Address: Faculty of Applied Social Sciences, University of Applied Sciences Munich, München, Germany. 
in long-term care should be evaluated based on evidence, to determine whether their use is justified, even though NCP has to be conducted as an integral part of professional nursing care $^{[3]}$ and as a legal obligation.

The purpose of this literature review is to identify NCP tools with desirable effects on residents' QoL and on nurses' quality of working life (QoWorkL) as relevant outcome parameters in long-term care (LTC) facilities. NCP tools are considered as the intervention investigated in the studies identified by the literature review. The comparison is nursing care planning as usual if the study is conducted with a quantitative design. Also qualitative studies were included into the review to take into account that QoL is an individual and highly subjective theoretical construct. Persons with LTC needs must integrate nursing assistance in their everyday life. Living in a nursing home with LTC needs means to live in an individual way one's life as normally as possible. Nursing care and medical treatment are in the background. For residents, institutions such as nursing homes are not only places to receive a service but their homes. ${ }^{[4]}$ Resident's QoL can be estimated holistically, i.e., encompassing the complexity of individual and multidimensional aspects. As Rubinstein suggests, QoL is the "stuff of everyday life' ${ }^{[5]}$ that is often hidden behind the clinical perspective on a person with health care needs. Care plans in LTC tend to be narrowly focused on clinical information and on information relevant for the legal and financial aspects of the organization. ${ }^{[6,7]}$ Residents, human beings living with a high health care need in a long-term care facility, are therefore a relevant population of the review. Resident's QoL is directly and indirectly affected by nure's QoL. For example, if nurses are suffering of distress their QoL mainly during working time is influenced negatively and their ability for empathy is decreasing. ${ }^{[6]}$ In healthcare and nursing empathy means a cognitive attribute involving an understanding of the patient's experience and perspective, as a separate individual, combined with an ability to communicate that understanding to the patient. ${ }^{[6]}$ Therefore empathy is a prerequisite for patient-centered care and patient-centered care increases resident's QoL.

Nurses working in long-term care facilities have a high workload and a high risk of distress with negative effects on quality of working life. A double effect of demographic change on nursing staff and on the European/especially German population as a whole ${ }^{[8]}$ causes a lack of qualified nurses for an increasing population of persons with advanced age and the need of care. The European Nurses' Early Exit Study (NEXT) shows the heavy burden on, and early exit of, nurses. ${ }^{[9]}$ Beside external effects an institution's organizational framework affects its employee's working life. Therefore nurses are a relevant population for this review, too.

In the review only studies should be included that investigate resident's QoL or nurse's QoWorkL as outcome. Being able to measure QoL valid instruments are necessary. As Oppikofer summerized in her systematic review a wide variety of instruments are available for measuring residents' QoL. ${ }^{[10]}$ The validity, quality, and capacity of these instruments are diverse. ${ }^{[11]}$

The development of valid instruments for measuring nurses' QoWorkL is helpful to evaluate the effects of NCPT on nurses' QoWorkL. Nurses' QoWorkL can be considered as a holistic concept and as a phenomenon with highly individual aspects in the domains of: professional work environment, autonomy, work satisfaction, professional relationships, role fulfillment, and benefits. ${ }^{[12]}$ Even these domains as multidimensional concepts can vary individually. ${ }^{[11]}$ To find out what really can help nurses to cope with the day-to-day challenges in the caring process of multi-morbid and often cognitively impaired persons with advanced age is a key factor for staff loyalty and quality of care. Nurses' perception of their QoWorkL during working hours has also an effect on residents' QoL. Therefore both concepts are interacting and must be evaluated simultaneously.

The literature shows that approaches for the evaluation of NCP depend on four main parameters: 1) formal structure; 2) nursing process comprehensiveness; 3) knowledge basis; and 4) conformity with actual care. ${ }^{[13]}$ Furthermore, there are several intervention studies that have investigated the effects of electronic care plans on these parameters. However, less is known about the effects of NCP tools on the course of everyday life in a nursing home. Urquhart and colleagues (2009) found no evidence of a change in clinical practice that resulted from a change of record system. ${ }^{[14]} \mathrm{NCP}$ tools are often concentrated on the fulfillment of legal and financial requirements of the insurance system. Residents' and nurses' requirements concerning coping with everyday life with high care needs were not the most important factors. When nursing care planning consumes time and resources, it is a good reason to ask if QoL as a relevant outcome in LTC can be improved by the use of NCP tools.

\section{Aim}

Against this background the underlying main assumptions for the review were: 1) NCP tools in LTC facilities are mainly constructed and used for fulfilling regulations and the needs of external regulatory organizations and authorities, but not for supporting nurses and residents with high care needs in managing their everyday (working) life. 2) Implemented NCP tools in nursing homes have no effects, desired ef- 
fects, or even side effects. 3) Little is known about the effects of NCP tools on residents' QoL and nurses' QoWorkL. The aim of the review was to identify NCP tools used in Continental Europe/Germany with desirable effects on residents' QoL and nurses' QoWorkL. Because of varying health systems and statutory framework of each country in the world only NCP tools authorized and used in Continental Europe/Germany were included into the review.

\section{Methods}

For defining the term 'nursing car planning' a comparison of the international definitions were systematically confirmed before starting with the literature review. As a result, we developed the following working definition:

NCP is a system of documents and tools. It is a technology and a service for nurses and persons requiring care that supports the planning and controlling of the nursing process in its five steps: 1) assessment, 2) diagnosis, 3) planning, 4) intervention (action) and 5) evaluation. From an economic point of view nursing care planning and documentation are not value creating but supportive processes with effects on the value creating process. It includes handwritten, digital (e.g. digital photo documentation of wounds), audio (e.g. audio file of an interview with the resident) and video (e.g. video analysis of facial action coding) tools. Its efficiency and effects have to be controlled regularly to monitor supportive function and avoid undue burden and negative side effects for the users. Nurses and persons requiring care are the primary end-users of NCP tools.

In order to understand the supportive function of NCP tools, we first have to understand the planning process. ${ }^{[15]} \mathrm{NCP}$ is often narrowed to its documents as a result of the nursing process. However, NCP is a complex procedure of managing a high variety of information that requires interaction with the resident, nurses, other professionals, and family caregivers. A NCP tool is a set of instruments and methods to monitor and control the nursing process; it is a complex technology with an effect on its end-users. It has individual and varying meanings for the users and their daily routine.

\section{Data sources and search strategy}

A systematic literature search from 1995 to 2014 in PSYNDEX, WISO-Net, PubMed, CINAHL, GeroLit, and the Cochrane Library was performed to identify studies investigating the effects of NCP tools on residents' QoL and nurses' QoWorkL. In addition, a manual search in German scientific nursing journals, 'Pflege' (1999-2014) and 'Pflege \& Gesellschaft' (1996-2014) was conducted and snowball strategies were used, such as screening eligible papers' reference lists, reviewing grey literature, and contacting experts in the field. A Boolean search strategy was used, incorporating truncated search terms and potential synonyms synchronized with databases' thesaurus. After an initial search, the strategy was elaborated and documented for each database in a table that shows the name of the database, the search strategy, limiters, and number of matches. In the study selection and data extraction process a peer-review system was integrated. Two reviewers screened eligible records based on pre-specified eligibility criteria. Inclusion and exclusion criteria were defined in advance. For inclusion, the identified records had to fulfil the following criteria:

- Time period: 1995 until March 2014

- The intervention was related to a NCP tool, either as a whole system of different components or one or more single components

- The NCP tool was used in the LTC facilities for persons of advanced age (over 65 years)

- Investigated effects included: nurses' QoWorkL as a holistic concept and/or related aspects, and/or residents' QoL as a holistic concept and/or related aspects

- Due to country-specific health and social care systems and their statutory frameworks, only NCP tools investigated in Continental European/German LTC facilities were included in this review.

- Publication was in English or German language (because of reviewers' limited language skills) studies with mixed-method designs were included because of the high individuality and subjectivity of QoL as a outcome and to include studies that focus on nurses' and residents' perceptions during the use of NCP tools

- Methodological quality of the study was a minimum of 'fair' following Evan's hierarchy of evidence. ${ }^{[16]}$

Randomised controlled trials (RCT) show the statistical probability of effects, such as increasing QoL (efficacy). Qualities such as residents' and nurses' perceptions and individual meanings concerning QoL when using NCP tools in clinical practice under everyday conditions (effectiveness) may be disregarded in pure quantitative study designs. Therefore, studies with mixed-method designs were included into the review to narrow the gap between absolute efficacy and effectiveness. If documentation should not 'take away from patient care', ${ }^{[3]}$ then the effectiveness of a NCP tool, its feasibility and appropriateness observed under everyday conditions should be analysed. For sophisticated analysis of study design criteria, SQUIRE guidelines (Standards for QUality Improvement Reporting Excellence) ${ }^{[17]}$ were used for the quantitative design, and ENTREQ guidelines (ENhancing Transparency in REporting the synthesis of Qualitative research) were used for the qualitative research design. ${ }^{[18]}$ For ranking the evidence, the Evans hierarchy was applied. ${ }^{[16]}$ 
In case of inaccurate fulfillment of criteria, a third, external reviewer was asked to screen the full text. The screening process from the total number of matches to the inclusion of relevant studies follows PRISMA (Preferred Reporting Items for Systematic Reviews and Meta-Analyses) guidelines. ${ }^{[19]}$ In addition, the side effects of NCP tools were monitored in the analysis. Residents are not only indirectly affected by NCP tools, but also directly when they are involved in a standardized assessment instrument, for instance. Side effects are evident both for residents and for nurses professionally using NCP tools. For example, Händler-Schuster and colleagues discovered that nurses feel incompetent when operating with a standardized instrument for assessing a resident's emotional state. Missing options for coding the individual's emotional status generated feelings of dissatisfaction, of decreased self-determination, and of decreased competence. Residents themselves feel anger from being observed and rated. ${ }^{[20]}$ These side effects have to be weighed against desirable effects.

For the outcome, residents' QoL, we used the following terms: 'quality of life', 'patient satisfaction', 'resident satisfaction', and 'lived experience'. For nurses' QoWorkL for internet database keyword searches, we used the terms: 'job satisfaction', and 'quality of working life'. The combination with the terms 'nursing care plan* OR nursing record* OR documentation' was carried out with the Boolean operator
ÁND' to focus the search on studies investigating QoL in relation to the use of NCP tools. Because of the varying search terms in combination with the Boolean operator OR we have got a high number of matches. Search terms for the outcome were varied because QoL is a complex, multidimensional construct. In QoL research, often single aspects or different terms are used for the construct QoL. A big amount of full texts $(n=205)$ were included and analysed for avoiding the exclusion of relevant studies.

\section{RESULTS}

Out of 1,190 matches, 205 full texts were analysed and 6 records were included in the narrative synthesis. Quality of life as a holistic concept was not used as a primary endpoint but relevant aspects of it were.

\subsection{Results for residents' quality of working life}

In total, 922 potentially relevant reports were found for the residents' endpoint QoL in databases and 78 by manual search (see Figure 1). After selecting duplicates, 998 reports from the databases and manual search were screened by reading abstracts; 834 reports could be excluded after this screening process. 164 relevant full texts were read and analysed by using pre-defined inclusion and exclusion criteria. At the end of the selecting and reviewing process, 3 reports could be included in the narrative synthesis of content analysis.

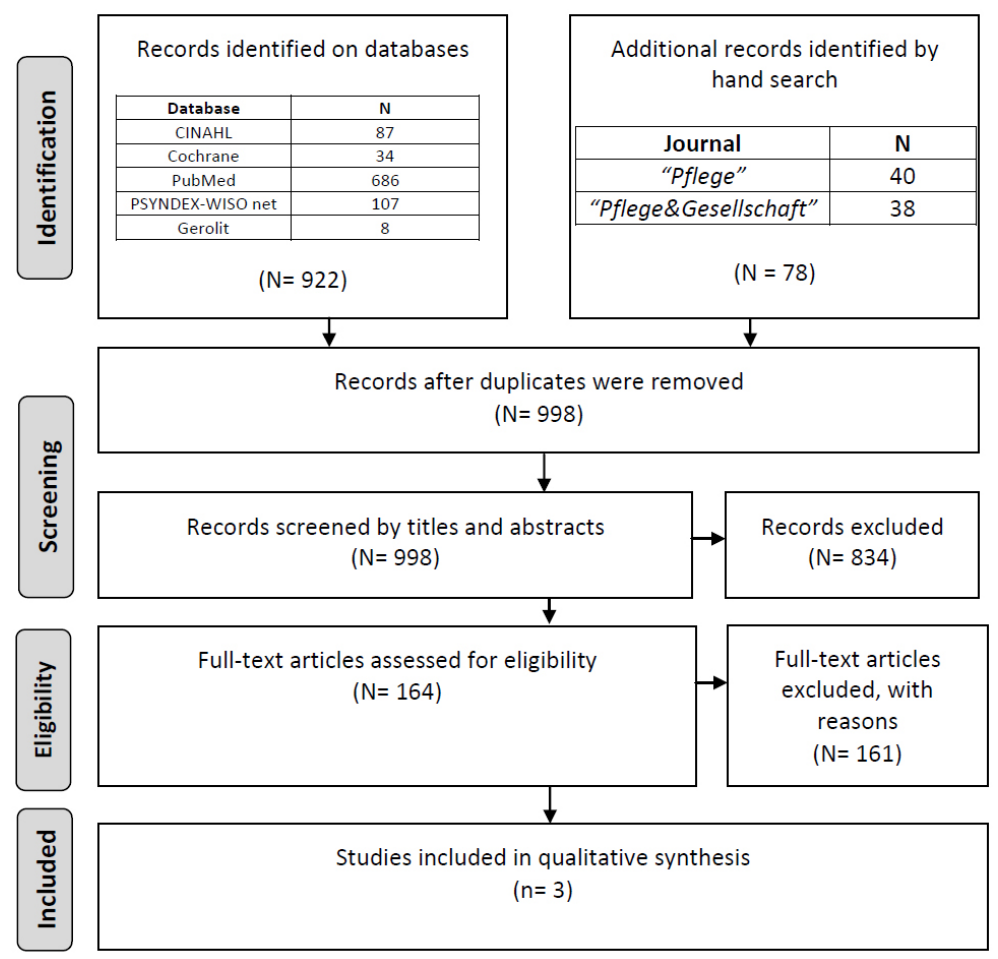

Figure 1. Results of the screening process of residents' quality of life (QoL) (PRISMA 2009 Flow Diagram) ${ }^{[19]}$ 


\subsection{Results for 'nurses' quality of work life'}

With the search strategy we identified 115 results from databases and 78 results by manual search in nursing science journals. After selection for redundancies, a total of 192 abstracts were screened to exclude irrelevant reports (n =151), and 41 full texts were analysed. 37 full texts were excluded for certain reasons, some of which are exemplarily listed in Table 1. Finally, 4 reports were included in the review. The whole extraction process is shown in Figure 2.
One study ${ }^{[21]}$ was identified that was already included in the endpoint 'residents' QoL'.

\subsection{Characteristics of included studies}

In the scope of this short report, only an overview can be given of the NCP tools that were identified by search strategy and included in the literature review. In Table 2, evidence level, outcome factors investigated in the study, indications for positive effects on residents' QoL, and nurses' QoWorkL are summarized.

Table 1. Frequent reasons for the exclusion of full-text analyzed studies with example

\begin{tabular}{|c|c|}
\hline Reason for exclusion with example & Explanation \\
\hline $\begin{array}{l}\text { There is no analysis of the impact/correlation } \\
\text { between care planning tool/system and relevant } \\
\text { outcome parameters (Qol/QoWorkL) }\end{array}$ & $\begin{array}{l}\text { The nursing care planning tool per se is analyzed (frequently in relationship with an } \\
\text { intervention, e.g. the implementation of an IT-based nursing documentation system, } \\
\text { staff training in care planning, etc.). Impact analyzes are made with regard to the quality } \\
\text { and the completeness of the documentation, not with regard to QoL. }\end{array}$ \\
\hline $\begin{array}{l}\text { Example: in der Schmitten J., Lex K., Mellert C., } \\
\text { Rothärmel S., Wegscheider K. \& Marckmann G. } \\
\text { (2014) Patientenverfügungsprogramm: } \\
\text { Implementierung in Senioreneinrichtungen. Eine } \\
\text { inter-regional kontrollierte Interventionsstudie. } \\
\text { Deutsches Ärzteblatt. 111(4): 50-57. }\end{array}$ & $\begin{array}{l}\text { Well-controlled intervention study with installation of an advanced-care planning } \\
\text { (ACP) tool. Clear description of the intervention ACP with inter-professional and inter } \\
\text { sectoral communication und documentation tool; Qol and QoWorkL were not analyzed } \\
\text { as primary outcome parameters, which leads to the exclusion; but there is a relevance } \\
\text { for further research of the relationship between ACP and Quality of end-of-life } \\
\text { (QoEnd-of-life); Because of publication's actuality it was not available in PubMed, so it } \\
\text { was procured within the scope of snowball-method. }\end{array}$ \\
\hline $\begin{array}{l}\text { Analysis of the completeness of care planning } \\
\text { and documentation with regard to the complete } \\
\text { representation of each step of the nursing } \\
\text { process; but no analysis of the impact for } \\
\text { outcome parameters (Qol/QoWorkL) }\end{array}$ & $\begin{array}{l}\text { The quality of care planning is assessed concerning to completeness of the nursing } \\
\text { process; no analysis of users' perceptions of QoL or relevant aspects of QoL when } \\
\text { working with the care planning tool. }\end{array}$ \\
\hline $\begin{array}{l}\text { Example: Bartholomeyczik, S. (2004) } \\
\text { Qualitätsdimensionen in der } \\
\text { Pflegedokumentation-eine standardisierte } \\
\text { Analyse von Dokumenten in Altenpflegeheimen. } \\
\text { Pflege. 17(3): 187-195. }\end{array}$ & $\begin{array}{l}\text { Standardized analysis of care planning with regard to the completeness and accordance } \\
\text { to the nursing process; the author used a quantitative and explorative evaluation study } \\
\text { design; no analysis of users' perceptions of QoL when working with the nursing care } \\
\text { planning tool. }\end{array}$ \\
\hline $\begin{array}{l}\text { The study analyzed the relationship between care } \\
\text { planning tool and the relevant outcome } \\
\text { parameters (Qol/QoWorkL), but it was not } \\
\text { conducted in Continental Europe/Germany; }\end{array}$ & $\begin{array}{l}\text { Study was not conducted in Continental Europe/Germany: The basic assumption of the } \\
\text { review was: With the introduction of statutory nursing assurance system in Germany } \\
1995 \text { nursing care planning changed fundamentally. NCP-tools in German } \\
\text { LTC-facilities are mainly constructed and used for fulfilling regulations and the needs } \\
\text { of external regulatory organizations like authorities but not for supporting nurses and } \\
\text { residents in managing their everyday (work-) life with high care needs. }\end{array}$ \\
\hline $\begin{array}{l}\text { Example: Urquhart, C., Currell, R., Grant, M. J., } \\
\text { Hardiker, N. R. (2009). Nursing record systems: } \\
\text { effects on nursing practice and healthcare } \\
\text { outcomes. Cochrane Database of Systematic } \\
\text { Reviews. 21(1): 1-66. }\end{array}$ & $\begin{array}{l}\text { Systematic review conducted in 2000, updated in } 2003 \text { and 2008, with high quality and } \\
\text { relevance for the research question; the review analyzes studies that investigated the } \\
\text { relationship between care planning and relevant outcome parameters (QoL, } \\
\text { QoWorkL/job satisfaction, patient satisfaction with nursing care, work satisfaction, job } \\
\text { turnover, sick time use, nurses' satisfaction with the new documentation system); many } \\
\text { interesting and specific references to the state of research (but with the Anglo-American } \\
\text { area as the principal area) and the need for research. The review was excluded because } \\
\text { no study was conducted in Continental Europe/Germany. }\end{array}$ \\
\hline $\begin{array}{l}\text { Other setting, other population than long-term } \\
\text { care (LTC) of people with advanced age }\end{array}$ & $\begin{array}{l}\text { Most of the studies found in the review were conducted in the outpatient setting, in } \\
\text { community nursing or in acute care hospitals but not in LTC of the elderly. }\end{array}$ \\
\hline
\end{tabular}

Excellent evidence for positive effects on relevant aspects of resident's QoL was found for the NANDA-I nursing diagnoses, mainly due to Müller-Staub and colleagues' (2007) well-conducted systematic review with 36 included studies. $^{[22]}$ A nursing diagnosis is the result of a judgement process made from the nurse's point of view by integrating 
the patient's perception of his or her situation. Medical diagnosis cannot substitute for nursing diagnosis, because of the latter's valuable focus on the patient's individual experience of disease or life processes and patient's individual reaction to a disease. Müller-Staub and colleagues found increasing evidence that the nursing diagnostic process is effective for better understanding patients' problems. Vice versa, this understanding is important for maintaining and promoting QoL, even though a direct correlation cannot be proved. Nurses' training in diagnostics from the beginning of their initial education is a necessary requirement for the quality of the diagnostic process and of the resulting diagnoses. This could be a crucial point, because nursing diagnosis are not an integral part of nurses' initial education in every country, as well as in Germany.

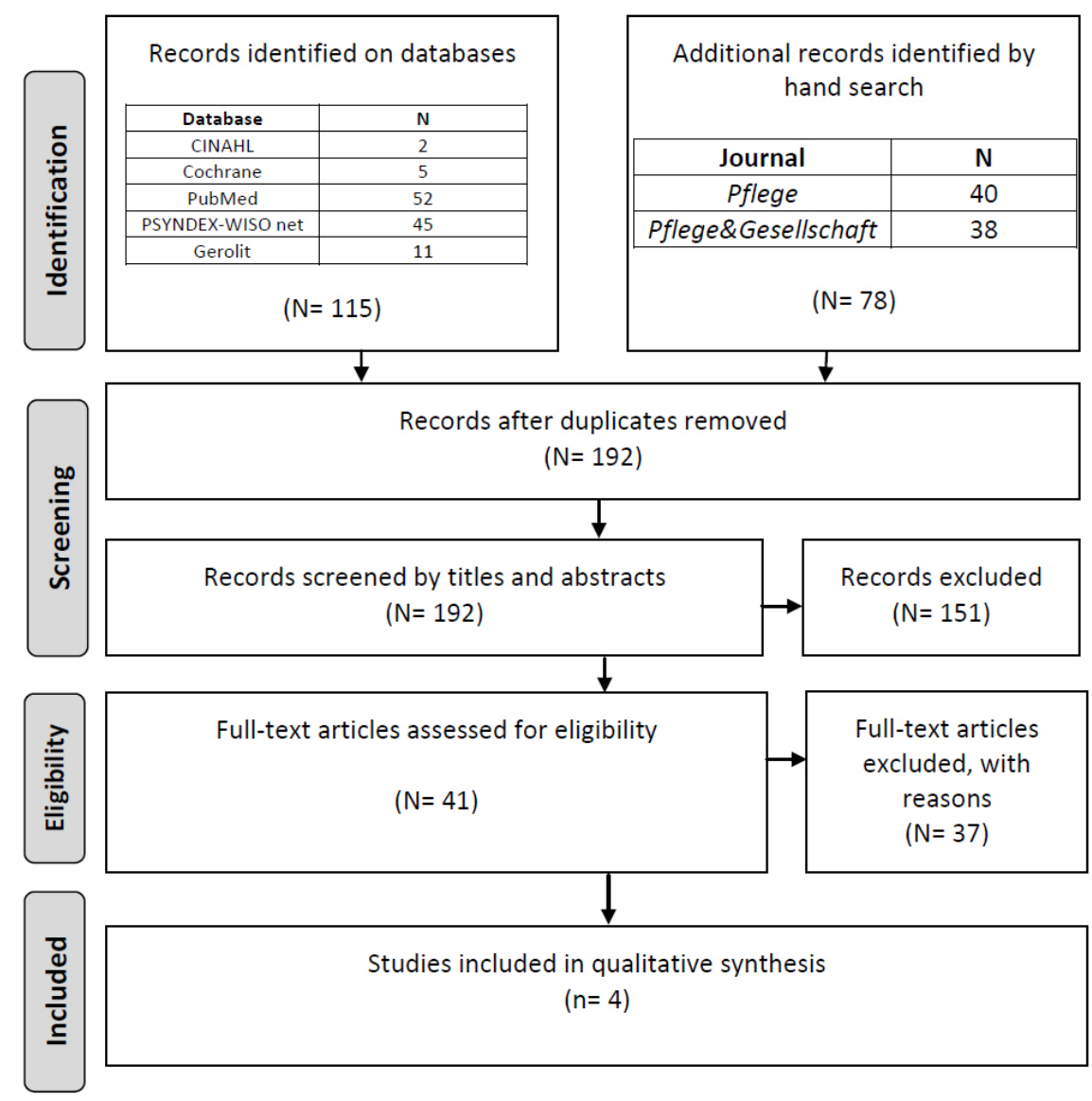

Figure 2. Results of the screening process of nurses' quality of working life (QoWorkL) ${ }^{[19]}$

For persons with cognitive impairment due to dementia, feelings in the moment are very important because of limited memory. Dementia is a highly relevant phenomenon in LTC. The DEMIAN II-concept (DEmenzkranke Menschen in Individuell bedeutsamen AlltagssituationeN) is a specific assessment tool for identifying emotionally meaningful situations in the everyday life of the resident with dementia. ${ }^{[21]}$ Based on assessment information, nursing interventions can be planned to promote positive emotions. The assessment tool is combined with case discussions. This NCP tool was empirically validated in 25 German nursing homes with 98 residents suffering from dementia from 2007 until 2010. The study shows a mixed-method design with a before and after measurement (pre- and post-test design), a control group

Published by Sciedu Press design, a proxy assessment of psychological state by observation and video analysis, and self-assessment by the resident. Residents' immediate emotional response on nursing interventions based on the emotion-specific assessment and residents' subjective QoL was in 75 percent of all analysed situations positive. In comparison with the group with care planning as usual positive situations were in the intervention group significant higher. A test for the power of effects and the sampling strategy were not described in the record, hence the study was ranked at level 'good'. We contacted the authors of the study report for several times to get more information about the study results but didn't get any answer. The project should be monitored by nursing managers and researchers. 
Table 2. Characteristics of the 6 studies included in the review (one tool, DEMIAN-II, was included for both outcome parameters QoL and QoWorkL, hence in total $\mathrm{n}=6$ studies were included)

\begin{tabular}{|c|c|c|c|c|}
\hline $\begin{array}{l}\text { Nursing care } \\
\text { planning tool }\end{array}$ & $\begin{array}{l}\text { Reference, } \\
\text { publication } \\
\text { date }\end{array}$ & $\begin{array}{l}\text { Evidence- } \\
\text { level } \\
\text { Evans } \\
2003\end{array}$ & $\begin{array}{l}\text { Outcome } \\
\text { parameter }\end{array}$ & Sample size and study design \\
\hline $\begin{array}{l}\text { NANDA-I nursing } \\
\text { diagnosis }\end{array}$ & $\begin{array}{l}\text { Müller-Staub, } \\
\text { M. et al. } 2007\end{array}$ & excellent & $\begin{array}{l}\text { Resident's } \\
\text { QoL }\end{array}$ & $\begin{array}{l}\text { Out of } \mathrm{N}=395 \text { reports analyzed by their } \\
\text { abstracts } \mathrm{N}=86 \text { full texts were analyzed. } \mathrm{N}= \\
31 \text { studies were included into the systematic } \\
\text { review (MEDLINE/CINAHL: } 29 \text {, Cochrane: } \\
\text { 2). Additionally } \mathrm{n}=5 \text { studies found by hand } \\
\text { search were included. Total simple size of } \\
\text { studies investigating effects of NANDA-I } \\
\text { nursing diagnosis was } \mathrm{n}=36 \text {. } \\
\text { Systematic review following strict and } \\
\text { transparent rules; included studies were } \\
\text { conducted in different settings }\end{array}$ \\
\hline
\end{tabular}

DEMIAN-II-

structured assessment and intervention

planning with focus

on individual

situations with

impact on positive

emotions

Project B3-

Promoting

emotional support of

people with

dementia-An

intervention program

for caregivers competences in the
Berendonk,

C. et al. 2011

Kruse A. et

al. 2011

(project

report: $2^{\text {nd }}$

Feb. 2007-

$31^{\text {st }}$ March

2008)
IdA (Innovative

dementia-oriented

assessment system):

understanding

approach in

diagnostics combined

with structured,

interdisciplinary case

conferences

Project A1 -

Development and

Evaluation of an

assessment

instrument for

systematically

collecting

information about

"patient view" in

LTC of residents with

dementia

IT-based nursing care

planning system

(electronic care

plans) with handhelds

Holle, D. et

al. 2011

fair

good

QoL

nurse's

QoWorkL

A total of $\mathrm{n}=200$ nurses and $\mathrm{n}=80$ persons with dementia from 20 nursing homes were acquired for the institutional care research track.

Controlled, cluster-randomized trial with intervention

Controlled, not randomized intervention study

Nurse's perception of burden was assessed

before $(\mathrm{n}=106)$ und after $(\mathrm{n}=71)$

intervention ( 9 months);

Assessment of nurse's perception of burden

(14 items), nurse's perception of working

conditions (11 items) and working

satisfaction ( 2 items) with a structured

questionnaire based on a 4-point Likert scale

A qualitative study design with narrative interviews of $n=25$ residents, assessed as dement; a qualitative analysis is planned that delivers categories for the structure of nursing care planning; qualitative analysis and results were not transparent in the report. Updated results were asked by direct Email-contact with the authors of the report, but no response; therefore the report was ranked "fair/poor"

Intervention study with a pre-post-design; pilot-testing of a IT-based nursing care planning system with handhelds in a nursing home (sampling by occasion) with 66 places; structured interviews with nurses, head nurses (ward manager) and one person of the commercial management; in total $\mathrm{n}=16$ persons were interviewed; because of methodological weaknesses the study was ranked "fair"

Intervention study: implementation of an IT-based nursing care planning tool, called "sic-Pflegeassistent" in 3 nursing homes (sampling by occasion) that worked with a paper-based nursing care planning system

"SIC-Pflegeassistent" IT-based nursing care planning system with handhelds

$\begin{array}{ll}\text { Kreidenweis, } & \text { poor } \\ \text { H. } 2009 & \text { QoWorse's }\end{array}$

before; standardized and structured survey of nurses and external collaborating partners such as physicians and therapists; no exact description of sample size and other methodological weaknesses lead to rank the study report as "poor"
Indications for positive effects on residents' QoL and nurses' QoWorkL implications for nursing management

Müller-Staub et al. found a significant correlation between quality of nursing diagnosis and patient's satisfaction with need of care assessment ( $p \leq .03$ is reported) Nursing diagnosis tend to be effective for better understanding patient's problems from patient's point of view, a relevant basis for a patient-centered care with implications not only for quality of care but also for resident's QoL.

In the first time period of the study positive effects on resident's QoL were observed because of significant more positive emotional reactions in individual meaningful situations compared to conventional nursing care. possible positive effects on relevant aspects of nurse's QoWorkL because of better relationships between care team members; perceived work load and burden will be measured in a second project step by MBI-D (Maslach Burnout Inventory-German version) a relevant study for both outcome parameters, resident's QoL and nurse's QoWorkL that should be monitored by nursing research and nursing quality management;

effects on both sides, on the side of the residents and on the side of the nurses are relevant for quality of care.

Possible positive effects on relevant aspects of nurse's QoWorkL because of a better understanding of challenging behavior; better understanding of resident's and nurses' insights can release from burden and help nurses to cope with challenging behavior; Further development and research of the tool should be monitored by nursing management.

Possible positive effects on relevant aspects of resident's QoL because of resident's priorities and needs are systematically assessed and taken into account in the nursing intervention planning process.

Further development and research of the tool should be monitored by nursing management.

Possible positive effects on relevant aspects of nurse's QoWorkL: work satisfaction, feelings of being appreciated, nurse's perception of an optimized working process such as practice-leading assessment of resident's care-need; handheld-based nursing care planning tools and their effects on working processes should be monitored by nursing management.

Possible positive effects on relevant aspects such as workload and work satisfaction of nurse's QoWorkL; Nurses' perception of being controlled as a side-effect was investigated; $60 \%$ of nurses participating in the survey reported about a feeling of being controlled;

Positive effects on feelings of safety while handling the tool; perceptions of saving time, and of less workload were reported by $93 \%$ of nurses participating in the survey. 
The European NEXT study showed a higher percentage of nurses in nursing homes compared to other settings (hospitals and home care), with a correlation between leaving the job and emotional exhaustion. ${ }^{[23]}$ Understanding challenging behaviour from the point of view of the resident with dementia can be a key factor to minimize the nurse's burden. The 'IdA' tool (Innovative dementia-oriented Assessment), is used simultaneously with structured, interdisciplinary case discussions to support this understanding process. ${ }^{[24]}$ Using the IdA tool, nurses can gain deeper insights into a resident's perception of the situation and can avoid personalizing challenging behaviour. The study was conducted in the framework of a national state programme of Germany, called 'InDemA'. The aim of this state programme is the interdisciplinary implementation of quality instruments for the care of persons with dementia. In a well-controlled intervention study, nurses' perception of burden was assessed before and 9 months after intervention. 106 nurses from 15 nursing homes were interviewed for their perception of burden before (to) intervention and 71 nurses after intervention. Nine months after intervention (t1), the percentage of nurses who named the feeling of time pressure decreased by $18 \%$. The percentage of nurses who were satisfied with working conditions had increased by $12 \%$. The perception of time pressure, burden and overall work satisfaction are important aspects of QoWorkL. The study was ranked at level 'fair'. The before and after design of the intervention study was well-controlled. The non-randomized sample showed a drop-out rate of 33\%. Reasons why $\mathrm{n}=35$ nurses had left the study were not explained in the record. Sampling strategy and effect analysis were not transparent.

In project 'A1' conducted by Naegele and colleagues an intervention planning and evaluation tool was developed to focus the nursing process on residents' priorities. ${ }^{[25]}$ The short report was identified by manual search and shows less information about the content of the tool and the methodology. Therefore, it was ranked at 'fair to poor'. Because of its potential for residents' QoL-focused NCP, the study was included in the narrative synthesis. Further reports about this tool should be monitored.

Two studies were found that evaluated IT-based NCP systems with handheld devices and their impact on QoWorkL aspects. $^{[26-28]}$ Since nurses' perceptions were already involved in the product development process, these aspects were systematically included in the development of the tool. The record's lack of transparency in methodology led to a rating level of 'fair to poor', although the study has a wellcontrolled design. Forty-four nurses were asked in face-toface interviews about their perceptions after the introduction of an IT-based tool, called 'sic-Pflegeassistent'. Data from

Published by Sciedu Press relevant factors of nurses' QoWorkL such as feelings of safety while handling the tool, time saved, and workload were collected. Nurses' feelings of being controlled as a side effect of the tool were also assessed. Some $39 \%$ (out of $n$ $=44$ ) of the nurses working with the tool reported feelings of being more controlled since the implementation of the ITbased tool. There is increasing evidence internationally that the feeling of being controlled causes distress in nurses ${ }^{[29]}$ Distress has negative effects on QoWorkL.

\section{Discussion}

Although the search strategy was carefully developed and broadened for capturing the whole variety of the concepts QoL, QoWorkL and NCP, it cannot be ruled out that studies fulfilling the inclusion criteria were missed. There are national specific regulations for NCP. Different legal norms for liquidation of health care services, specific regulations for external quality control, varying stages of nursing professionalization make it difficult to generalize the implications for research and nursing management worldwide. Nevertheless the tools identified as effective tools for promoting residents' QoL and nurses' QoWorkL are relatively independent from these legal regulations. Nurse's diagnostic investigation is internationally accepted as one important step in the nursing process. The most effective tools found in this review refer to the nursing diagnostic process with an understanding approach. Focusing nursing diagnostic investigation on the understanding process with the resident seems to have desirable effects on QoL on both sides, on the side of the resident and on the side of the nurse. Further research with these potential effective tools should be conducted internationally using randomized controlled designs. The power of effect was not statistically tested and the sample strategies of the included studies were not randomized-hence no reliable statement can be given for the statistical probability of effects. Future studies should also include qualitative designs in a mixed-method approach to adequately take into account the individual perceptions of nurses and residents when using $\mathrm{NCP}$ tools. The qualitative designs, such as semi-structured interviews or observational approaches with video analysis, of the studies, identified in this review, show with high reliability users' perception of effectiveness under everyday circumstances. Following NANDA-I nursing diagnoses in the diagnostic process does not only mean to use the standardized terms but to validate the diagnosis with the patient. Patient's point of view concerning his (or her) own health or life process is a crucial factor in validating nursing diagnosis. This process of understanding on the basis of a confidential relationship between nurse and resident might have a positive effect on QoL on both sides, on the side of the nurse and 
on the side of the resident. If cognitive impairment affects the resident in a long-term care facility this understanding process is much more complex and there is a high risk of misunderstanding. Nurses might personalize challenging behavior such as shouting dirty words. When using the IdA (Innovative dementia-oriented Assessment ${ }^{[24]}$ - tool already in the assessment process, nurses might gain deeper insights into resident's perception of the situation. They might be able to understand resident's behavior from his (or her) point of view and from resident's biographic background. As a result nurses feel no more guilty or responsible for this behavior what means less emotional and psychological stress As McGillis Hall and colleagues (2006) emphasized these are important aspects influencing nurses' QoWorkL. ${ }^{[12]}$

With the DEMIAN II-concept (DEmenzkranke Menschen in Individuell bedeutsamen AlltagssituationeN) as a specific assessment tool for identifying emotionally meaningful situations in the everyday life of the resident with dementia ${ }^{\text {[21] }}$ resident's QoL can be promoted systematically. Nurses can use the information systematically gathered with this tool in the assessment for intervention planning. Creating moments of joy and positive emotions means QoL for the resident and for the nurse. Healthcare services are co-creative processes. The resident as producer and not only as a consumer must be involved in the process actively and in particular adequately because of his (or her) physical, mental and/or psychological impairment. NCP tools should support this co-creative processes with the aim to promote QoL.

IT-based NCP tools with handheld devices investigated by Lüngen and colleagues (2008) and Kreidenweis (2014, 2009) support nurses, handling a large amount of data, getting promptly information of the resident and managing daily documentation duties. ${ }^{[26-28]}$ Nurses who work with the 'sicPflegeassistent' showed feelings of safety, time saved and decreased workload while handling the tool. As a side-effect feelings of being controlled were reported by the interviewed nurses. Because there is increasing evidence internationally that the feeling of being controlled causes distress in nurses $^{[29]}$ the tool should be verified in a larger population with a quantitative design by monitoring side effects and desirable effects. Deeper insights into nurse's perceptions while working with the tool can be got when combining the quantitative design with narrative interviews. Such interviews might also show the reasons from nurse's point of view why they feel controlled. These identified reasons may help in the developing process of IT-based tools and their organizational implementation.

Although there is increasing development of valid instruments for measuring nurses' QoWorkL ${ }^{[12]}$ as a holistic con- cept and it is recognized that work organization has an impact on nurses' working life and job satisfaction, these instruments were not found in the included studies. This finding is comparable to McGillis and colleagues' critique of the lack of organizational evaluation of QoWorkL with valid indicators. ${ }^{[12]}$

Due to the complexity, multidimensionality, and individuality of the QoL-concept and due to QoL is often not investigated as a holistic concept, it was necessary to broaden search strategy. The result was a large number of matches. If search strategy was narrowed too early, important aspects of QoL, evaluated as outcome factors in the identified studies of this review, may not have been found. In effect, this means a time consuming review process with a high number of full text papers that have to be analysed. Researchers and nurse managers should monitor the development of effective NCP tools, and focus should be broadened from a clinical perspective to an overall view of user's perspective, especially user's perceived QoL. Programs for disabled people for example are working with person-centered planning and there is a growing body of international evidence that person-centered planning has desirable effects on QoL. ${ }^{[30]}$

\section{Conclusion}

A systematic and wide-ranging search was conducted and although studies with mixed-method designs were included, little is known about NCP tools' effectiveness and appropriateness with regard to QoL. Although there is an increasing discussion about skills shortage and high workload in nursing, QoWorkL is a little-regarded concept in the development of NCP tools and technologies. Nevertheless there is evidence for NCP tools with desirable effects on resident's QoL and nurse's QoWorkL. The further development and evaluation of these tools should be monitored by nursing researchers and nursing managers. Besides clinical practice challenges, the statutory framework and the health financial system require detailed documentation of what nurses are doing for the legalization and liquidation of their services. The obligation to write extensive records, feelings of not having enough time, of being controlled, or having failed are stress factors besides many others, including the challenging behaviours of residents with cognitive impairment. Increasing downtime due to mainly psychological health problems ${ }^{[9,31]}$ and decreasing QoWorkL are consequences. In long-term care facilities we need therefore innovative and supportive technology as one possible starting point to relieve nurses and to assist them to promote residents' QoL. NCP tools are important components of this supportive technology. Hence, care planning tools should be designed in a way that supports nurses in daily work with residents and in their efforts to de- 
velop resident's QoL. Technology such as NCP tools should serve the main end-users, such as nurses and residents, and not vice versa.

\section{ACKNOWLEDGEMENTS}

This work was supported by the Federal Ministry of Health and Nursing Bavaria, Germany (Z2/0271.01-1/96). No other commercial or non-commercial support was given.

\section{CONFlicts OF InTEREST Disclosure}

The authors declare that there is no conflict of interest.

\section{REFERENCES}

[1] Bundesanstalt für Arbeitsschutz und Arbeitsmedizin BAuA (ed.). INQA Initiative, neue Qualität in der Arbeit. Zeitdruck in der Pflege reduzieren. 2. Aufl. Bundesministerium für Familie, Senioren, Frauen und Jugend, Potentiale für ein selbständiges Leben. Unter Mitarbeit von Schneekloth Ulrich. 2010

[2] Munyisia EN, Yu P, Hailey D. How nursing staff spend their time on activities in a nursing home: an observational study. J ADV NURS. 2011; 67(9): 1908-1917. PMid:21466577 https :/doi.org/10.11 $11 / j .1365-2648$. 2011.05633.x

[3] College of Nurses Ontario (CNO). Practice standard. Documentation, revised 2008. http://www. cno.org/Global/docs/prac/4 1001_documentation.pdf

[4] Herold-Majumdar A, Behrens J. Lebensqualität im Fokus des Qualitätsaudits in der Langzeitpflege. Der Lebensqualitäts-Index (LQIndex) - ein "Zauberstab" mit begrenzter Wirkung. Quality of life in the Focus of Quality Audits in Long-Term Care. The Quality of Life Index (QoL Index) - A Magic Wand with Limited Efficacy. Das Gesundheitswesen. 2012; 74(12): 806-811. PMid:22322335

[5] Rubinstein RL. Resident Satisfaction, Quality of Life and Lived Experience as Domains to Be Assessed in Long-Term Care. In CohenMansfield, J., Ejaz, F. K., Werner, P. (eds), Satisfaction Surveys in Long-Term Care. New York: Springer Publishing Company; 2000. 13-28 p.

[6] Patricia B, Stephan L, Emilie PS, et al. Relationship between empathy and well-being among emergency nurses. In: J Emerg Nurs. 2015; 41: 323-8.

[7] Hansebo G, Kihlgren M, Ljunggren G. Review of nursing documentation in nursing home wards - changes after intervention for individualized care. Journal of Advanced Nursing. 1999; 29(6): 1462-1473. https://doi.org/10.1046/j.1365-2648.1999.01034.x

[8] Hamm I, Seitz H, Werding M (ed). Demographic Change in Germany. The Economic and Fiscal Consequences. 213 pp. 2008; Berlin, Heidelberg: Springer.

[9] Hasselhorn HM, Conway PM, Widerszal-Bazyl M, et al. NEXT study group. Contribution of job strain to nurses' consideration of leaving the profession-results from the longitudinal European Nurses' Early Exit Study. SJWEH. 2008; (6): 75-82.

[10] Oppikofer S. Lebensqualität bei Demenz. Eine Bestandsaufnahme, Sichtung und Dokumentation bestehender Instrumente zur Messung von Lebensqualität bei Menschen mit schwerer Demenz. Universität Zürich, Zentrum für Gerontologie, Zürich. 2008.

[11] Hickey A, O'Boyle CA, McGee HM, et al. The schedule for the evaluation of individual quality of life. In Joyce C. R. B., O'Boyle C. A., McGee H. (eds.), Individual quality of life. Approaches to conceptualisation and assessment. Amsterdam: Harwood Academic Publishers; 1999. 119-134 p.

[12] McGillis Hall LDD, O'Brien P, Tranmer J, et al. Quality Worklife Indicators for Nursing Practice Environments in Ontario. Determining the Feasibility of Collecting Indicator Data. Ontario: The On- tario Ministry of Health \& Long-Term Care (ed). 2006. Available from: http://www.mcgillishall.com/wp-content/uploads /2010/05/QWIN_Report.pdf

[13] Ehrenberg A, Ehnfors M, Smedby B. Auditing nursing content in patient records. Scandinavian Journal of Caring Sciences. 2001; 15(2): 133-141. https://doi.org/10.1046/j.1471-6712.2001.000 $11 . \mathrm{x}$

[14] Urquhart C, Currell R, Grant MJ, et al. Nursing record systems: effects on nursing practice and healthcare outcomes. Cochrane Database of Systematic Reviews. 2009; 21 (1): 1-66.

[15] Munkvold G, Ellingsen G, Monteiro E. From plans to planning the case of nursing plans. Proceedings of Group 07. Sanibel Island, Florida, USA. 2007.

[16] Evans D. Hierarchy of evidence: a framework for ranking evidence evaluating healthcare interventions. Journal of Clinical Nursing. 2003; 12 (1): 77-84. https://doi.org/10.1046/j.1365-270 $2.2003 .00662 . x$

[17] Ogrinc G, Mooney E, Estrada C, et al. The SQUIRE (Standards for Quality Improvement Reporting Excellence) guidelines for quality improvement reporting: explanation and elaboration. Qual Saf Health Care. 2008; 17(1): i13-i32.

[18] Tong A, Flemming K, McInnes E, et al. Enhancing transparency in reporting the synthesis of qualitative research: ENTREQ. BMC Medical Research Methodology. 2012; (12): 181-189.

[19] Moher D, Liberati A, Tetzlaff J, et al. Preferred reporting items for systematic reviews and meta-analyses: the PRISMA statement BMJBMJ. 2009; 339 (8): 332-336.

[20] Händler-Schuster D, Geschwindner H, Oppikofer S, et al. Wie erleben Erfasserinnen den Umgang mit der Observed Emotional Rating Scale? Pflege. 2010; 23(3): 181-189. PMid:20509114 https://doi.org/10.1024/1012-5302/a000038

[21] Berendonk C, Stanek S, Schönit M, et al. Biographiearbeit in der stationären Langzeitpflege von Menschen mit Demenz: Potenziale des DEMIAN-Pflegekonzepts. Z Gerontol Geriat. 2011; (44): 13-18

[22] Müller-Staub M, Lavin MA, Needham I, et al. Pflegediagnosen, interventionen und -ergebnisse - Anwendung und Auswirkungen auf die Pflegepraxis: eine systematische Literaturübersicht. Pflege. 2007; 20 (6): 352-371. PMid:18357749 https://doi.org/10.1024/ 1012-5302.20.6.352

[23] Simon M, Tackenberg P, Hasselhorn HM, et al. Auswertung der ersten Befragung der NEXT-Studie in Deutschland. 2005; Universität Wuppertal. http://www . next . uni-wuppertal . de Accessed 26 Mai 2015.

[24] Holle D, Halek M, Mayer H, et al. Die Auswirkungen der Verstehenden Diagnostik auf das Belastungserleben Pflegender im Umgang mit Menschen mit Demenz in der stationären Altenhilfe. Pflege. 2011; 24(5): 303-316. PMid:21964934 https://doi .org/10.1024/10 $12-5302 / \mathrm{a} 000143$

[25] Naegele G, Schönberg F, Schulz-Hausgenoss A. Entwicklung und Evaluation eines Instruments zur Erfassung des patient view 
von Demenzkranken in vollstationären Pflegeeinrichtungen als Grundlage für eine Ressourcen erhaltende Pflege. PFLEGE \& GESELLSCHAFT. 2005; 10 (1): 50-51.

[26] Lüngen M, Gerber A, Rupprecht C, et al. Effizienz der computergestützten Dokumentation in Pflegeheimen - eine Pilotstudie. Pflege Zeitschrift. 2008; 61(6): 334-339.

[27] Kreidenweis H. Projekt-Bericht.: Evaluation der Einführung von Pflegedokumentations-Software bei leben \& wohnen, 2014; Stuttgart. Available from: http://fordoc.ku-eichstaett.de/1146/1/ Projekt-Bericht-LeWo-08.pdf

[28] Kreidenweis H. Nützliche Technik: Der Computer hilft in der Pflege. Altenpflege. 2009; (5): 29-31.
[29] Engstöm MM, Skytt B, Nilsson A. Working life and stress symptoms among caregivers in elderly care with formal and no formal competence. Journal of Nursing Management. 2011; 19(6): 732-741. PMid:21899626 https:/doi.org/10.1111/j.1365-2 $834.2011 .01270 . \mathrm{x}$

[30] National Disability Authority. Guidelines on Person Centred Planning in the Provision of Services for People with Disabilities in Ireland. 2014. Available from: http://www.nda.ie/cntmgmtnew.nsf / 0/12AF395217EE3AC7802570C800430BB1/\$File/main.pdf

[31] Brause M, Horn A, Büscher A, et al. Gesundheitsförderung in der stationären Langzeitversorgung-Teil II. Bielefeld: Veröffentlichungsreihe des Instituts für Pflegewissenschaft Universität Bielefeld (IPW). 2010. 10-144 p. Available from: https : / www . un ibielefeld.de/gesundhw/ag6/downloads/ipw-144.pdf 